\title{
Yeast Killer Factor-induced Turbidity Changes in Cells and Sphaeroplasts of a Sensitive Strain
}

\author{
By H. BUSSEY \\ Department of Biology, McGill University, P.O. Box 6070, Montreal Ior, Quebec, Canada
}

(Received 5 October I973; revised 5 December I973)

SUMMARY

When a culture of a sensitive yeast strain is treated with yeast killer-protein, there is an increase in turbidity. This killer protein-induced turbidity increase coincides with the loss of cellular ATP, and appears to be caused by increased light scattering owing to a reduction in volume of the treated yeast cells. Sphaeroplasts prepared from sensitive cells were also sensitive to killer protein, and a culture showed a large increase in turbidity when treated with killer protein. The increase in turbidity of sphaeroplasts was not accounted for by a change in volume, but did correlate with killer protein-induced alterations in membrane permeability, and is consistent with a killer protein-induced alteration in light scattering of the yeast cell membrane.

\section{INTRODUCTION}

Killer strains of the yeast Saccharomyces cerevisiae produce a group of extracellular proteins, differing in molecular size, that kill sensitive yeast strains of this species (Woods \& Bevan, 1968; Bussey, 1972). During the killing process, changes in the membrane permeability of sensitive cells were observed (Bussey, 1972). In sensitive yeast treated with killer protein, ATP leaked from the yeast cells and accumulated in the medium in amounts several times greater than the total ATP present in control cultures. Efflux of glucose from such sensitive cells also increased, though efflux of leucine from the cellular pools increased only slightly and no detectable loss of cellular macromolecules was found. These permeability changes, especially the loss of ATP, probably account for the co-ordinate inhibition of macromolecular synthesis seen in killer-treated cultures, and the findings are consistent with the killer protein acting on the yeast cell membrane. To further explore this possibility, we have re-examined an observation (Bussey, 1972) that there was a killer protein-induced increase in the turbidity of a sensitive culture.

\section{METHODS}

Strains and growth media. Killer yeast strain $\mathrm{K}_{12}$, sensitive strain $\mathrm{s}_{14}$, and a killer resistant mutant $\mathbf{R}_{14}$ derived from $\mathrm{s}_{14}$ were as described by Bussey, Sherman \& Somers (1973), and were grown on their yeast extract-peptone medium.

Sphaeroplasts were prepared by using the method of Hutchison \& Hartwell (I967) and used as described by Bussey et al. (1973).

Preparation of killer protein. Cell-free extracts of extracellular macromolecules were obtained from the culture fluid of killer strain $\mathrm{K}_{\mathbf{1 2}}$ by ultrafiltration and dialysis as described by Bussey (1972) and Bussey \& Sherman (1973). These extracts contained killer protein. The killing activity was determined by adding various killer concentrations to a growing culture of sensitive strain $\mathrm{s}_{14}$, and determining the number of viable yeast cells by plating on 
to yeast extract-peptone agar. Use of this method to determine the time course of killing effectively measured adsorption of killer protein to the yeast cells. The preparations used in these experiments had protein concentrations of 2 to $2.5 \mathrm{mg} / \mathrm{ml}$ and contained $1 \mathrm{O}^{11}$ to $4 \times 10^{11}$ killing units $/ \mathrm{ml}$, calculated from the multiplicity, $m$, obtained from the relation

where $S / S_{0}$ is the survival ratio.

$$
S / S_{0}=\mathrm{e}^{-m}
$$

Killer proteins were partially purified from the above extracellular extracts by precipitation with $10 \%(\mathrm{w} / \mathrm{v})$ polyethylene glycol 6000 (Baker). The precipitate was redissolved in $0 . \mathrm{I}$ M-sodium acetate-acetic acid buffer $\mathrm{pH}_{4.7}$ and the killer proteins separated on a Sepharose $4 \mathrm{~B}$ column (Bussey, 1972). The killer protein retained by the column was purified approximately I00-fold over the crude extracellular extracts, and was used as described below.

Yeast cell counts and cell volume determinations. Total number of particles and a histogram plot of particle number as a function of particle volume were determined by using a Coulter electronic particle counter (Model B) with distribution plotter attachment. Yeasts were grown and diluted in yeast extract-peptone medium which had been filtered before sterilization through a Millipore HAWP $0.45 \mu \mathrm{m}$ filter. Sphaeroplasts were grown and diluted in prefiltered yeast extract-peptone medium supplemented with $20 \%$ (w/v) D-sorbitol. A IO0 $\mu \mathrm{m}$ aperture was used, with an aperture current of I/0.354 and an amplification factor of $\mathrm{I}$.

ATP measurement. ATP was estimated by using luciferase as described by Bussey \& Sherman (1973).

Turbidity estimations. Culture turbidity of both yeasts and sphaeroplasts was measured in a Gilford model 240 spectrophotometer at $600 \mathrm{~nm}$, with a path length of $\mathrm{I} \mathrm{cm}$. In a typical experiment, $5 \mathrm{ml}$ of a yeast culture with and without killer were grown in culture tubes on a roller-drum at 22 to $24{ }^{\circ} \mathrm{C}$, and turbidity was measured at time intervals. Similar results were obtained using a Klett-Summerson photocolorimeter with a blue filter.

Dry weight measurement. Yeast cells ( 15 to $30 \mathrm{mg}$ ) were filtered on to preweighed glassfibre filter discs (Whatman G F/A), washed with distilled water, and dried at $90^{\circ} \mathrm{C}$ to constant weight.

Sorbitol uptake. Cultures of sensitive strain $\mathrm{s}_{14}$ were grown on yeast extract-peptone medium plus I·I M D-sorbitol. $\left[{ }^{14} \mathrm{C}\right]$-D-sorbitol (Amersham/Searle CFB-28) was added with and without killer to a final concentration of $\mathrm{I} \cdot \mathrm{I} \mathrm{M}$ and a specific activity of $0.98 \mathrm{mCi} / \mathrm{mol}$. Yeast cells were filtered on to glass-fibre discs, washed with $10 \mathrm{ml} \mathrm{I} \cdot \mathrm{I} \mathrm{MD}$-sorbitol and counted in an Intertechnique SL-40 liquid scintillation spectrometer.

Photomicroscopy. A Zeiss photomicroscope with a Zeiss Ukatron microflash unit was used to take photographs of yeast cells and sphaeroplasts by bright-field and phase-contrast illumination respectively. Yeast cells were assumed to be prolate ellipsoids, and their volumes were calculated from the measured major and minor axes. Sphaeroplasts were assumed to be spherical and their volumes calculated from the measured radii.

\section{RESULTS}

\section{Turbidity effects in yeast cells}

A growing culture of sensitive yeast treated with killer protein showed an increase in turbidity compared with an untreated control culture (Fig. I $a$ ). The increase in turbidity started after a lag period of about 30 min following addition of killer protein, and reached a maximum 


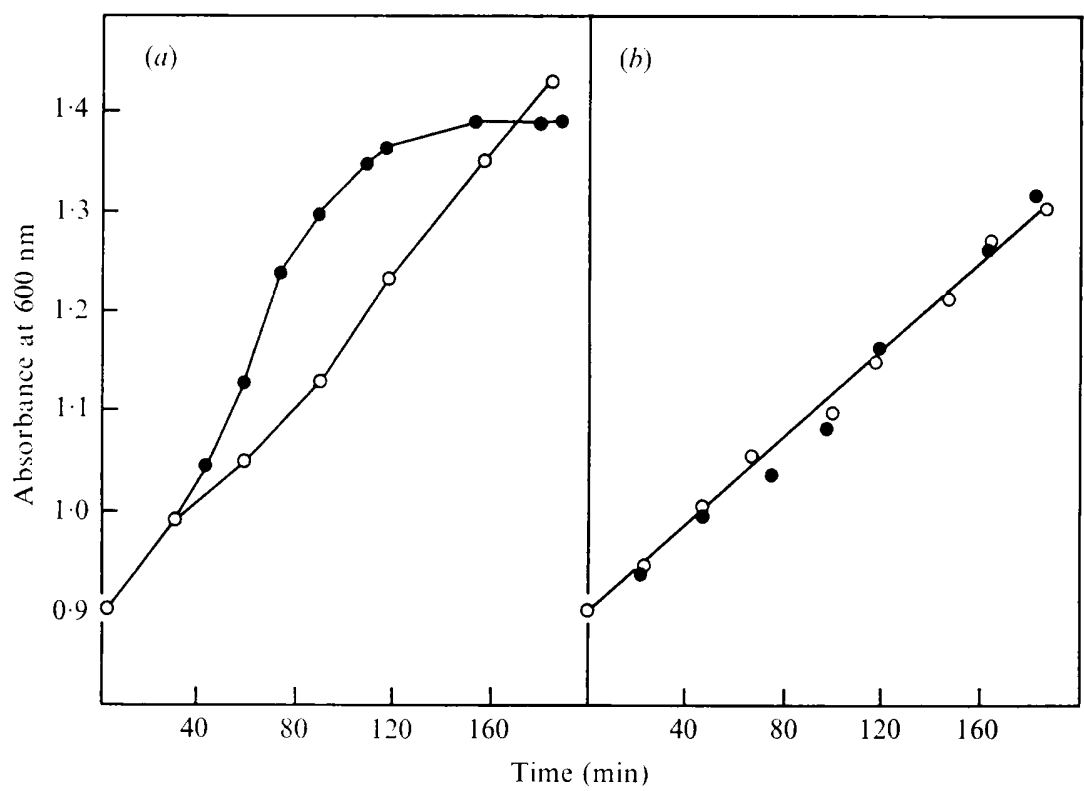

Fig. I. Turbidity of sensitive and killer-producing cultures on treatment with killer protein. Killer (multiplicity 9.5) was added at time zero to cultures growing at 22 to $24{ }^{\circ} \mathrm{C}$. (a) Sensitive strain $\mathrm{s}_{14}$; (b) killer-producing strain $\mathrm{K}_{\mathbf{1 2}} . \mathrm{O}$, Control; $\mathbf{O}$, culture plus killer.

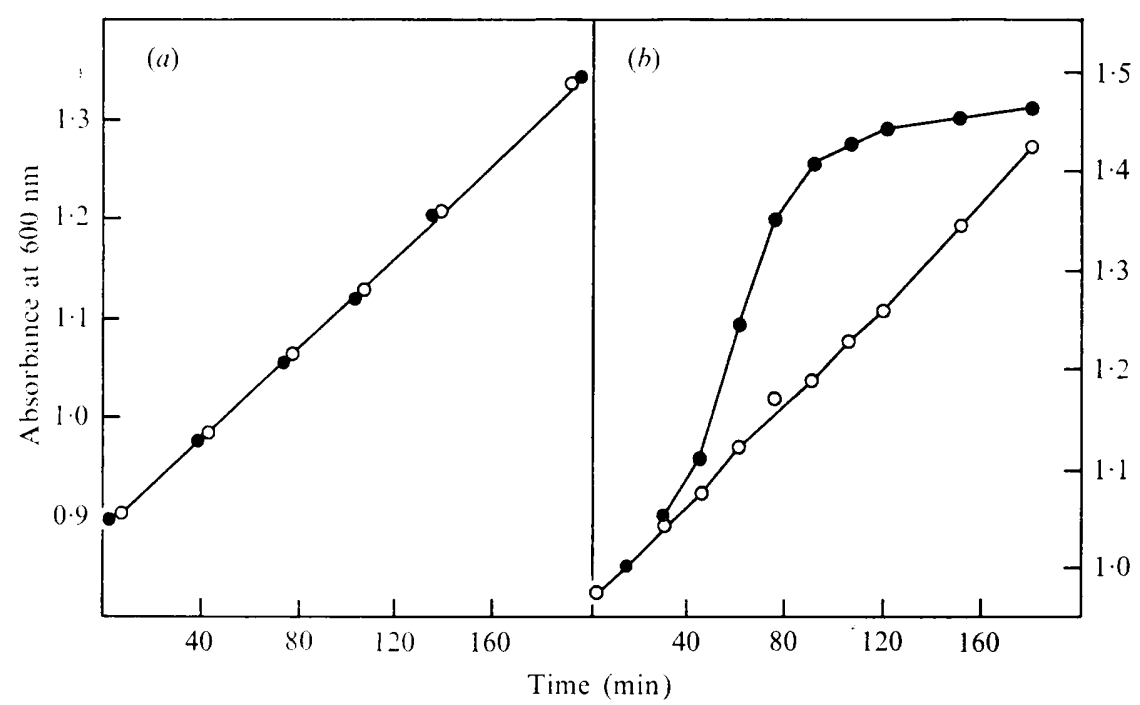

Fig. 2. (a) Turbidity of killer-resistant mutant $\mathbf{R}_{\mathbf{1 4}}$ on treatment with killer protein. Killer (multiplicity $9 \cdot 6$, on parent strain $s_{14}$ ) was added at time zero to the mutant culture growing at 22 to $24^{\circ} \mathrm{C}$. (b) Turbidity of sensitive strain $\mathrm{s}_{\mathbf{1 4}}$ on treatment with a partially purified killer protein. Killer protein (multiplicity 7.7) was added at a final concentration of $19 \mu \mathrm{g} / \mathrm{ml}$ as in $(a)$. $O$, Control, , culture plus killer.

at $\mathrm{I} 60 \mathrm{~min}$; thereafter the turbidity fell slowly (10\% reduction after $4 \mathrm{~h}$ ). The turbidity effect was specific for sensitive yeast strains. Killer-producing strains were immune to killer action (Bevan \& Makower, 1963; Bussey et al. 1973), and a culture showed no increase in turbidity when treated with killer protein (Fig. $\mathbf{I} b$ ). A killer-resistant mutant, $\mathbf{R}_{\mathbf{1 4}}$, isolated 


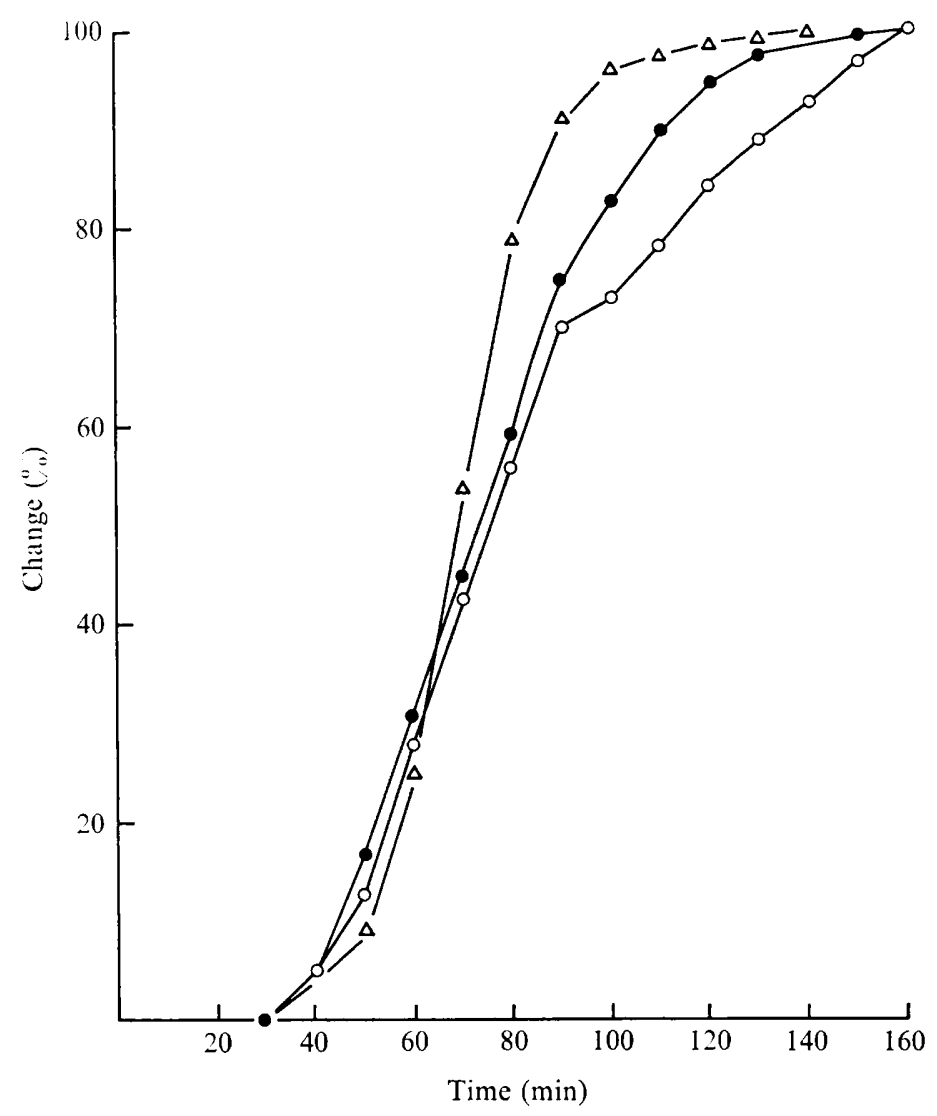

Fig. 3. The kinetics of kilier protein-induced ATP leakage from yeast cells, and turbidity changes in cultures of yeast cells and sphaeroplasts. Cells and sphaeroplasts of sensitive strain $s_{14}$ were grown as described, killer (multiplicity 8.0 to 9.5 ) was added at time zero. $\Delta$, Sphaeroplast turbidity increase; $\bullet$, yeast cell turbidity increase (average of three separate experiments); 0 , ATP leakage from yeast cells (average of two separate experiments).

from sensitive strain $\mathrm{s}_{14}$, and unable to bind killer protein to sites on the cell wall (Bussey et al. 1973), also showed no turbidity increase on killer treatment (Fig. 2a). Evidence that the turbidity increase was caused by killer protein and not by a contaminant in the concentrated extracellular proteins came from work with a killer protein component purified approximately I0o-fold over the crude extracellular proteins (see Methods). When this partially pure killer-protein preparation was added to a sensitive culture, it caused a turbidity increase similar to that seen with crude killer-protein extracts (Fig. $2 b$ ). Thus, the turbidity change was killer protein-induced and was a process associated with yeast killing. Loss of ATP from sensitive yeast coincided with the turbidity increase (Fig. 3), but these killerinduced effects occurred with a distinct lag after adsorption of killer protein to yeast cells, adsorption being $99 \%$ complete within 7 min of addition of killer protein.

The turbidity increase was a property of sensitive cells treated with killer protein and was not caused by cellular components that had leaked into the medium, because there was a negligible increase (less than $3 \%$ of the observed effect) in the absorbance at $600 \mathrm{~nm}$ of medium from which killed yeast cells had been removed by filtration. The turbidity effect was not caused by an increase in yeast cell mass (dry weight) or yeast cell number since both 


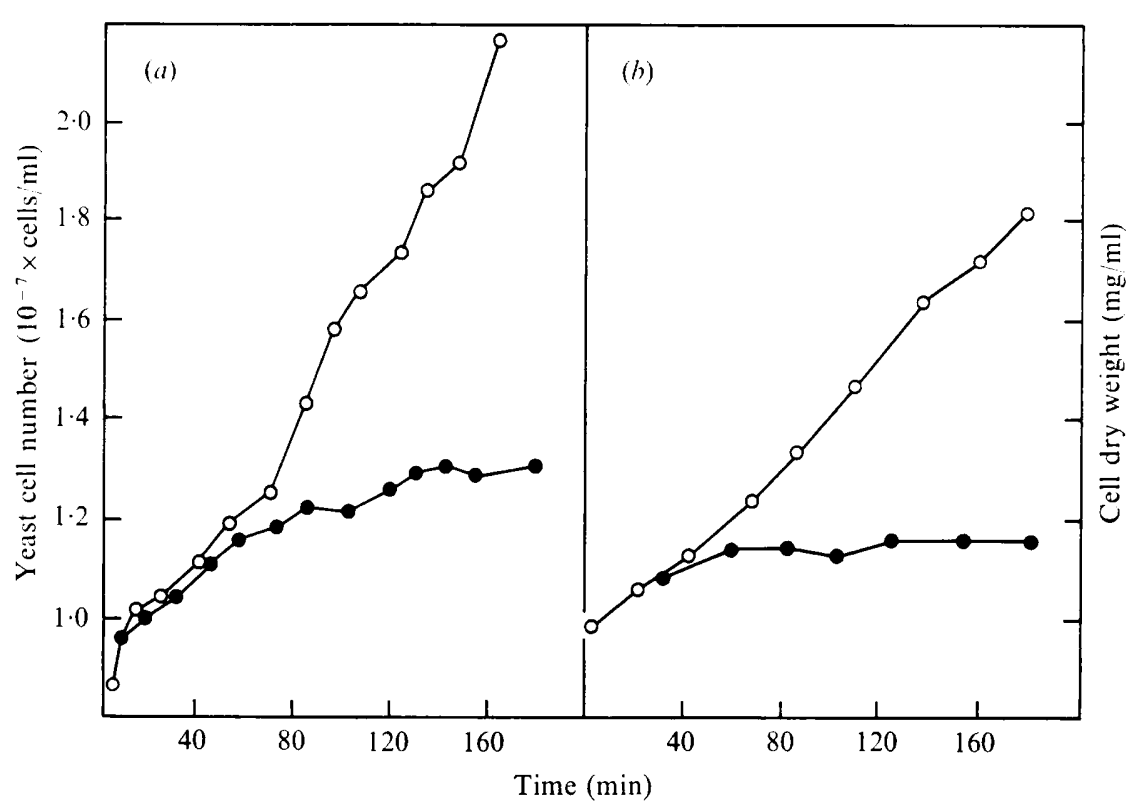

Fig. 4. Inhibition of increase in yeast cell number and dry weight of sensitive strain $\mathrm{s}_{\mathbf{1 4}}$ treated with killer protein. Killer, multiplicity $7 \cdot 7(a)$ and $8.5(b)$, was added to growing cultures at time zero. $(a)$, Cell number; $(b)$, cell dry weight. $\mathrm{O}$, Untreated control culture; $\bullet$, culture plus killer.

parameters were inhibited with a time course similar to the inhibition of synthesis of macromolecules (Fig. 4).

To test whether the turbidity increase was caused by a reduction in yeast cell volume (Koch, I96I; Knowles, I97I), cell volume was monitored in a culture following addition of killer protein. A marked decrease in cell volume was observed with a reduction in the volume range of the killer-treated yeast cell population (Fig. $5 a$ ). The kinetics of the volume reduction on killer treatment indicated that such reduction correlated with increase of turbidity. The Coulter counter detects yeasts with associated buds or yeast cell aggregates as a single unit, hence it was possible that variation in cell budding or aggregation was responsible for the apparent reduction in yeast cell volume. To test these possibilities, the volumes of individual sensitive yeast cells with and without killer treatment were measured from photomicrographs. Killer-treated cells were shown to be smaller than those in a control culture, mean volumes being 22 and $32 \mu \mathrm{m}^{3}$ respectively. The population differences were significant at the $2 \%$ level by the Mann-Whitney U test. Assuming the Jobst approximation (Koch, I96I), the culture absorbance should vary inversely with the two-thirds power of the yeast cell volume. Using the mean population volumes of killer and control cultures, the observed turbidity change agreed (within $25 \%$ ) with the expected change.

\section{Turbidity effects in sphaeroplasts}

Sphaeroplasts prepared from sensitive yeast strains remain sensitive to killer action (Bussey et al. 1973). Using a killer-resistant mutant, it was possible to identify two types of sites of killer action, one on the yeast cell wall removable with glusulase, and the other remaining on sphaeroplasts, presumably on the yeast cell membrane (Bussey et al. 1973). If the killer-induced turbidity changes seen in yeast cultures were caused by an altered cell membrane then it should be possible to detect killer protein-induced membrane changes in 


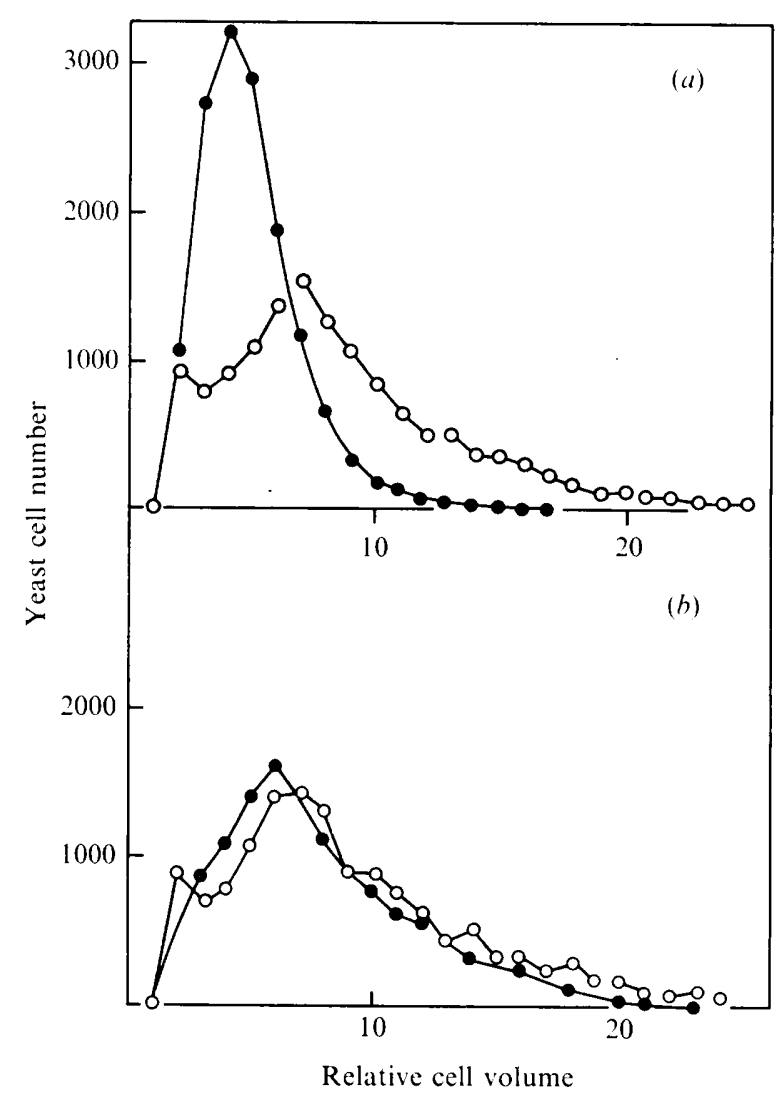

Fig. 5. Killer protein-induced cell volume changes in a culture of sensitive strain $\mathbf{s}_{\mathbf{1 4}}$. Killer protein (multiplicity 9.6 ) was added to a growing culture of $s_{14}$ and the volumes of the yeast cells in the population were measured at various times after killer addition using a Coulter counter. Yeast cell numbers in these populations increased with time; the data have been adjusted to give the same yeast cell number for each population. (a) Culture plus killer: $O$, immediately before killer addition; , after $175 \mathrm{~min}$. (b) Untreated control: $O$, after $5 \mathrm{~min}$;, after $17 \mathrm{I} \mathrm{min}$.

sphaeroplasts by a change in turbidity. A culture of growing sensitive sphaeroplasts showed a large increase in turbidity after treatment with killer protein (Fig. $6 a$ ), and this phenomenon occurred co-ordinately with both ATP loss and the turbidity increase seen in a sensitive yeast culture (Fig. 3). Sphaeroplasts made from yeasts of a killer-producing culture were immune to killer action (Bussey et al. 1973) and showed no turbidity increase when killer protein was added to a culture (Fig. $6 b$ ), though a slight reduction in growth rate was apparent. Thus, as with yeast cells, the turbidity change was associated with the action of killer protein.

Measurement of sphaeroplast volumes after killer treatment (Fig. 7a) showed no large change in volume such as that found in yeast cells. Growing sphaeroplasts did not divide, but increased in volume (Fig. $7 b$ ). Measurement of individual sphaeroplast volumes from photomicrographs also indicated that sphaeroplasts did not change volume on killer treatment and that there was no change in the degree of sphaeroplast aggregation. Attempts to mimic the increase of turbidity in sphaeroplasts by inhibition of energy yielding metabolism by 0.01 M-arsenate of $0.05 \mathrm{M}$-sulphite (Hartwell \& McLaughlin, I968), were unsuccessful.

If loss of metabolites from yeast cells were responsible for the reduction in yeast cell 


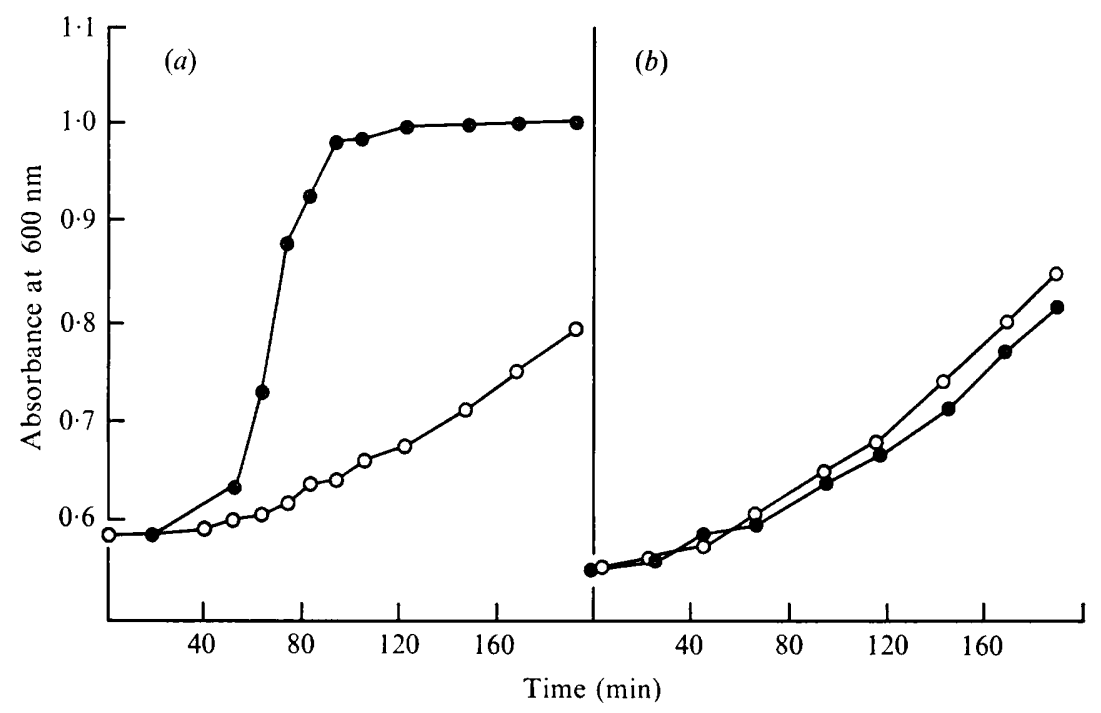

Fig. 6. Killer protein-induced turbidity changes in sphaeroplasts prepared from sensitive and killerproducing yeasts. Killer (multiplicity $9 \cdot 6$ ) was added at time zero to sphaeroplast cultures growing at 22 to $24^{\circ} \mathrm{C}$. (a) Sensitive strain $\mathrm{S}_{\mathbf{1 4}}$, (b) killer producing strain $\mathrm{K}_{\mathbf{1 4}}$. $\mathrm{O}$, Control; $\bullet$, culture plus killer.

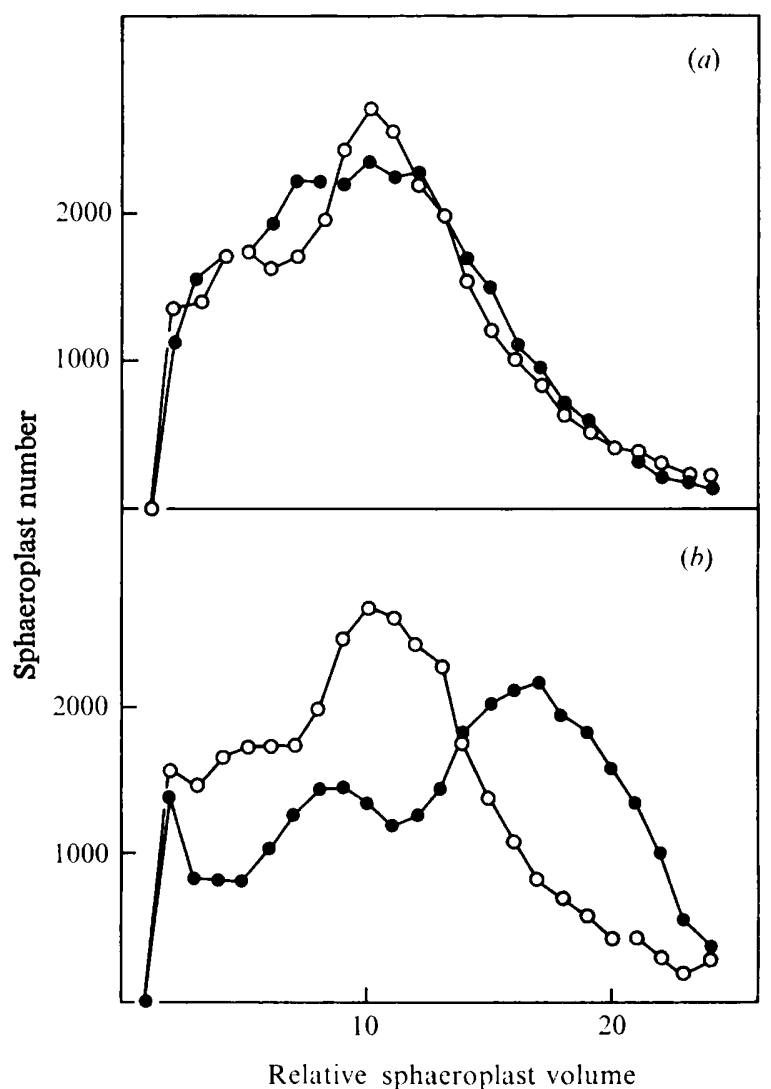

Fig. 7. Inhibition of volume increase in sensitive sphaeroplasts on killer-protein treatment. Killer (multiplicity $9^{\circ}$ ) was added to sphaeroplast cultures growing at 22 to $24^{\circ} \mathrm{C}$, and the volumes of the sphaeroplasts in the population were measured at various times after killer addition. (a) Culture plus killer: $O$, after $23 \mathrm{~min}$; $\bullet$, after $190 \mathrm{~min}$. (b) Untreated control: $O$, after $17 \mathrm{~min}$; $\bullet$, after $183 \mathrm{~min}$. 


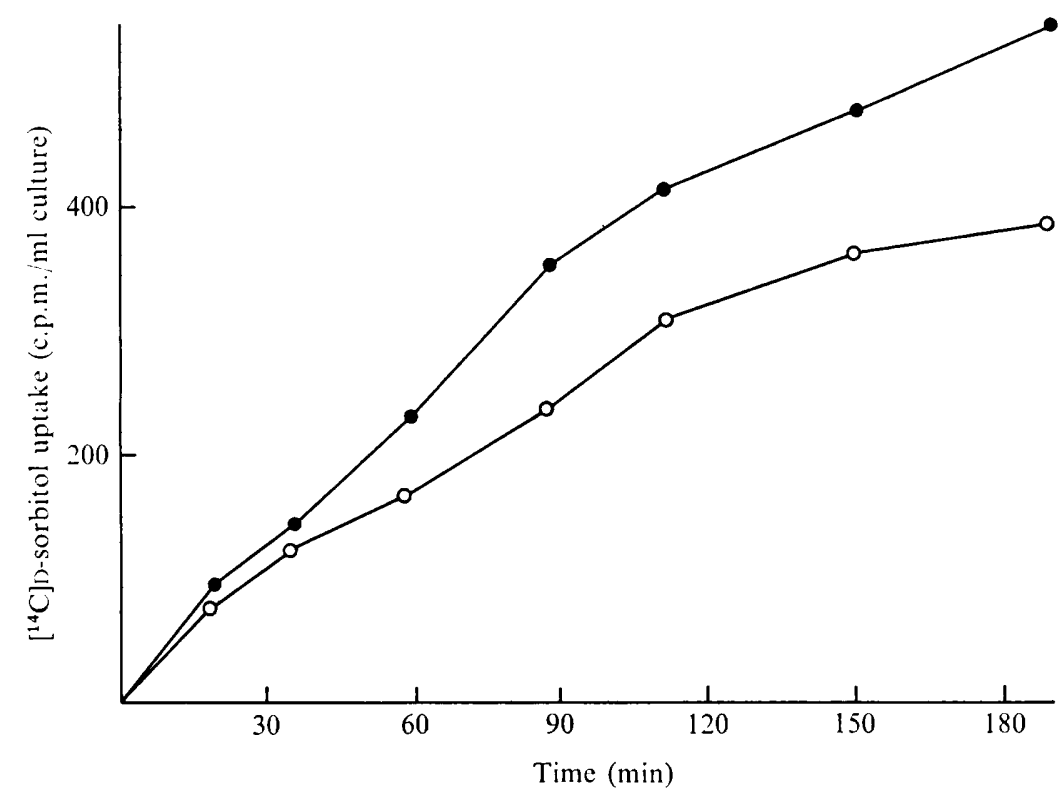

Fig. 8. Increased permeability of sensitive yeast cells to $\left[{ }^{4} \mathrm{C}\right] \mathrm{D}$-sorbitol on treatment with killer protein. Strain $\mathrm{S}_{14}$ was grown in $\mathrm{I} \cdot \mathrm{I} \mathrm{M}$-sorbitol at 22 to $24{ }^{\circ} \mathrm{C}$; at zero time, killer (multiplicity 7.9) was added with $\left[{ }^{14} \mathrm{C}\right] \mathrm{D}$-sorbitol and uptake into the yeast cells was measured. $\mathrm{O}$, Control; ๑, culture plus killer.

volume, it would be expected that a similar loss from sphaeroplasts suspended in an isotonic medium would lead to a reduction in sphaeroplast volume. A possible reason why this does not occur is that the killer protein-altered membrane becomes more permeable to sorbitol, the osmotic stabilizer in the medium. Sphaeroplasts could not have become freely permeable to sorbitol as this would have caused them to lyse (Knowles, 197I). A prediction from such an explanation is that killer protein-treated yeast cells would not decrease in volume if suspended in isotonic sorbitol. This was tested, and in isotonic (I.I M) sorbitol the killerinduced turbidity increase was reduced by about $70 \%$, though sorbitol did not reduce yeast cell death in the culture. A more direct test for increased sorbitol permeability of killertreated sensitive cells was to measure uptake of $\left[{ }^{14} \mathrm{C}\right]-\mathrm{D}$-sorbitol into yeast cells. A sensitive culture was grown in D-sorbitol; killer protein and $\left[{ }^{14} \mathrm{C}\right]$-D-sorbitol were added and uptake of labelled sorbitol was measured during the killing process (Fig. 8). An increase in the sorbitol permeability of killer-treated sensitive cells compared with untreated control cells was observed. From estimates of the yeast cell number, mean cell volume and the concentration and specific activity of the $\left[{ }^{14} \mathrm{C}\right]-\mathrm{D}$-sorbitol, it was calculated that at $180 \mathrm{~min}$ after sorbitol addition, the control and killer protein-treated yeast cells contained $\mathrm{I} 3$ to $25 \%$ respectively of the sorbitol concentration expected if the yeast were freely permeable to the substance.

\section{DISCUSSION}

These studies on the killer protein-induced turbidity changes in yeast cells and sphaeroplasts provide good evidence that the killer protein has an effect on the yeast cell membrane. It is difficult to offer an explanation for the turbidity increase/volume reduction effect in yeast cells that does not involve a killer protein-induced change in the cell membrane. One explanation for the reduction in yeast cell volume is that the killer protein alters membrane permeability leading to the loss of cellular components, e.g. ATP, intermediary metabolites 
and ions, which reduces the cellular osmotic pressure. If the osmotic pressure is involved in determining cell volume (Knowles, 1971) then the cells would shrink. A detailed evaluation of the sites of killer action and the membrane functions altered would be necessary to test this possibility.

Explanations for the killer protein-induced turbidity increase in sphaeroplasts would include some alteration of the cell membrane with change in light scattering, or some change in the absorbance, light scattering, or refractive index of the sphaeroplast contents. Assuming a common mechanism of killer action in yeast cells and sphaeroplasts in events subsequent to those occurring at the cell wall sites, then a membrane alteration would be the most likely.

It is not known whether the killer protein-induced turbidity increase in sphaeroplasts measures the primary membrane alteration, which in turn is responsible for the leakage of ATP and other cellular components, or whether the turbidity increase and ATP leakage are consequences of a killer protein-induced alteration of some separate primary event.

The time courses of the killer protein-induced turbidity effects in yeast cells and sphaeroplasts are very similar (Fig. 3); thus the lag period before the turbidity increase cannot be accounted for by the binding of the killer protein to the cell wall sites. Similarly, killer protein transfer from wall site to sphaeroplast site cannot be an event involved in generating the lag. The time course of the killer protein-induced turbidity change in sphaeroplasts, approximately $60 \mathrm{~min}$ at 22 to $24^{\circ} \mathrm{C}$, suggests that the effect could be caused either by a killer protein-induced conformational change in the membrane of the type suggested for colicin action (Changeux \& Thiery, 1967) or by diffusional rearrangement of proteins in a fluid mosaic membrane (Singer \& Nicholson, 1972) as observed in mouse-human cell hybrids (Frye \& Edidin, I970).

I thank R. G. E. Palfree for discussions, R. Cameron and D. Sherman for technical assistance and R. Lamarche for photography. This work was supported by grants from the National Research Council of Canada and the Quebec Ministry of Education.

\section{REFERENCES}

Bevan, E. A. \& Makower, M. (I963). The physiological basis of the killer character in yeast. In Proceedings of the i ith International Congress of Genetics, vol. I, p. 203 (abstract).

Bussey, H. (1972). Effects of yeast killer factor on sensitive cells. Nature New Biology 235, 73-75.

Bussey, H., Sherman, D. \& Somers, J. M. (I973). Action of yeast killer factor: a resistant mutant with sensitive spheroplasts. Journal of Bacteriology II3, I I93-I 197.

BusSey, H. \& Sherman, D. (1973). Yeast killer factor: ATP leakage and coordinate inhibition of macromolecular synthesis in sensitive cells. Biochimica et biophysica acta 298, 868-875.

Changeux, J. P. \& Thiery, J. (1967). On the mode of action of colicins: a model of regulation at the membrane level. Journal of Theoretical Biology 17, 3I 5-317.

FrYe, L. D. \& EDIDIN, M. (1970). The rapid intermixing of cell surface antigens after formation of mousehuman heterokaryons. Journal of Cell Science 7, 319-335.

Hartwell, L. H. \& McLaughlin, C. S. (I968). Temperature-sensitive mutants of yeast exhibiting a rapid inhibition of protein synthesis. Journal of Bacteriology 96, I664-I 67I.

Hutchison, H. G. \& Hartwell, L. H. (1967). Macromolecule synthesis in yeast spheroplasts. Journal of Bacteriology 94, I697-1705.

KNOWLES, C. J. (I97I). Salt induces changes in turbidity and volume of E. coli. Nature New Biology 229, I54-155.

Koch, A. L. (196I). Some calculations on the turbidity of mitochondria and bacteria. Biochimica et biophysica acta 51, 429-44I.

Singer, S. J. \& Nicholson, G. L. (1972). The fluid mosaic model of the structure of cell membranes. Science, New York I75, 720-73I.

Woods, D. R. \& Bevan, E. A. (1968). Studies on the nature of the killer factor produced by Saccharomyces cerevisiae. Journal of General Microbiology 51, I I 5-I 26. 